should be curtailed from six years, as it is now, to four years; and the aim should be to give 50 per cent of all children of school-age four years schooling in the local vernacular. Swahili, which is the only indigenous lingua franca, should be discontinued in schools, and its place taken by relatively unknown local tribal languages. It should be the aim of the educational authorities to provide a further four-year course for 10 per cent of the school-age population, and four years secondary schooling for 2 per cent of all the children who should be at school. It is preferable to site African schools not too near the towns. European supervisors should be placed over trained African teachers, for the time being. The prerequisite of a university degree for highly paid European teachers should sometimes be waived to make it easier to recruit men with an agricultural bent, who, by their presence in African schools, would inspire the 'natives' to become good farming folk.

However, the report of Mr. Binns and his colleagues is valuable on account of the stress it lays on $(a)$ the importance of research into those aspects, for example, wastage, of African education which now appear baffling; (b) founding teacher colleges of 100-200 students, with practising schools attached; (c) the encouragement of female education by relieving transport difficulties; (d) providing bedsheets, spoons, lavatories, and similar elements of prime necessity in boarding schools; (e) making teachers competent to teach Africans English in the intermediate and secondary schools ; $(f)$ erecting a suitable moral and religious basis to all education. Perhaps the most important-certainly the most wiseutterance in the entire report is the following: "The ideal school, if it were acceptable to parents, would be an interracial school. There are no insurmountable practical difficulties in the way of interracial education at any stage, but there are many difficulties in men's minds. Initiatives in this direction must therefore be the pioneer efforts of individuals who feel a call to experiment in this field . . . and because the task of government is eased as racial tensions are eased, such initiatives should receive moral and financial aid from the Government". One cannot help wondering why this does not appear in the official recommendations of the group.

Dr. Jeffery and his co-workers, who are convinced that "the potentialities of the West African have been demonstrated by actual achievement", had an easier task. The Phelps-Stokes Commission of 1920 had a Gold Coast member, Dr. Aggrey, on it ; and the implementation of its recommendations have probably been pursued much farther in West Africa than elsewhere.

But there are still many problems awaiting solution. For example, the group expressed its anxiety over the possibility of the local governments taking over responsibility of recurrent expenditure for education when the Colonial Development and Welfare Funds come to an end. The question of raising capital for the great educational expansion that is called for is another cause of worry for those responsible for educational development in West Africa. About a third of the probable annual expenditure of $£ 3$ million by the Nigerian Government will be absorbed by higher education. Is this proportion too high, in view of the great need for extending the frontiers of elementary education in the rural areas? Is it wise, at this critical stage, to build up an extravagant medical school to train only a handful of clinicians annually?
On the perennial question of the relationship between voluntary and governmental agencies, the commission agrees that a functional amicable relationship is gradually being built up in West Africa. The system whereby government grants voluntary bodies financial aid in the running of their schools is commended here, as in East Africa. The group records a consensus of informed African opinion that an entirely secular education is undesirable; but does not insist that the religious basis should be Christian. West Africa has a considerable Moslem population, and there are other religious groups.

Although the Jeffery committee commends tho "Accelerated Development Plan for Education in the Gold Coast" on both educational and administrative grounds, the bottleneck may prove to be the recruitment of staff. It is the same problem all over again. African graduates do not take up the teaching profession because the prospects of promotion are not great. Besides, expatriate staff receive much better emoluments, even under the African Governments which are emerging on the West Coast.

The Cambridge conference reconsidered all these questions under the following heads: $A$, Responsibility and Control ; $B$, Expansion of the Educational System; $C$, Teaching Profession; $D$, Organization and the Curriculum; $E$, Education and the Adult. The reports of the five study-groups of the conference and the plenary discussions on them are printed in this volume in an edited form. Mr. W. E. Ward, editor of the Colonial Office journal Overseas Education, in his private capacity put the material together. On the whole, the conference appears to have favoured the Jeffery approach rather than the Binns ; but many a reader will feel regret that the names of the speakers have been omitted from the dialogues.

As Sir Philip Morris states in his epilogue to the conference, its chief purpose was, obviously, in human relations. The whole purpose of education is in human relations ; for, in the language of the West African study-group, "education is the complex of actions and reactions between persons by which a nation prepares itself for its future by the dissemination of knowledge and skills and valid ideas of human dignity and fellowship". OuUmbe Bassir

\section{NUCLEAR PARTICLE LABORATORY AT QUEEN MARY COLLEGE, LONDON}

$T$

HE inauguration on June 23 of the Nuclear Particle Laboratory at Queen Mary College, University of London, marks what is probably the first occasion on which applied nuclear physics has been officially instituted in Great Britain as part of the undergraduate engineer's education. The laboratory has, however, a dual function to fulfil. In addition to the provision of practical work for undergraduates in the field best described as nucleonies, it also makes available facilities for research work relating to accelerating machines and gas discharges, where high-voltage electrical engineering, electronics, and nucleonics have a common frontier.

Taking the undergraduate work first, the subject designated 'nuclear energy' is offered to third-year mechanical and electrical engineers as one of a 
number of options from which part of the final year's work is selected. (This is now usual in schools of engineering in North America.) The course is therefore somewhat superficial compared to the other aspects of engineering, which receive three years study. However, it would be wrong to allow greater specialization at this stage in the new subject, even though it may be expected to develop extensively luring the active life of the present undergraduate opulation. The lectures are based mainly on the recently declassified information on nuclear reactor design, but also on general aspects of nuclear physics related to engineering. To obtain a suitable laboratory course to support such lectures, use is made of artificial radioactive sources, and particularly, antimony-beryllium neutron sources. These enable measuring techniques to be studied, which relate directly to engineering uses of radioisotopes as well as providing substance to some aspects of reactor theory, such as neutron distribution theory and calculations relating to cross-sections. It is hoped that it will eventually be possible to extend these experiments by the use of material enriched in fissile components. The whole subject is of general interest to engineers, as quite apart from the practical uses for which nuclear energy will become available, its development is an outstanding example of the logical and scientific processes by which the formulæ of theoretical physics can eventually be translated into engineering reality.

The research facilities offered by the Nuclear Particle Laboratory centre around the high-voltage equipment, which is not yet complete. A 1-MV. electrostatic generator has been in use, however, for examination of discharges in continuously evacuated systems, and similar work has been carried out at $100-200 \mathrm{kV}$. using rectifier sets. An impulse generator for $1 \mathrm{MV}$. shortly to be finished will at first be used on the same programme, though it is planned to develop, from this, a high-intensity electron accelerator. Interest has so far tended to be concentrated on the discharge phenomena at residual gas pressures, because this is often a practical engineering limitation in the design of accelerators, particularly D.C. accelerators of the electrostatic type. It has been found that preliminary discharges are obtained in such systems with characteristics which have not previously been investigated in any detail. Further apparatus in use includes a 5-MV. single impulse air-cored betatron which can be employed to give short X-ray impulses at higher voltages; but the intensity is, of course, much lower. An electron microscope is also in operation, providing both a further weapon for investigation of discharges (in so far as these originate in electrode surfaces) and an example of high-voltage equipment of interest to the biological faculties. Either a further D.c. generator or a radio-frequency accelerator will be installed next year, depending upon development of the present research groups.

The range of engineering activity has now extended over so wide a field that many feel that the undergraduate courses at universities may be in need of quite drastic modification. There is a wide divergence of opinion as to what form such modification should take; but perhaps a majority of crities believe that more emphasis on fundamental principles is needed, with less time spent on design study. The Nuclear Particle Laboratory at Queen Mary College, with an over-riding emphasis on the fundamental theory of matter, is a step in this direction.

\section{MECHANISM OF PROTOPLASMIC MOVEMENT}

\author{
By Prof. WILLIAM SEIFRIZ \\ University of Pennsylvania
}

7 HE streaming of protoplasm and the apparently autonomous movoment of particles within it have long been problems in biology, and many have been the theories to explain them. Protoplasmic flow has been attributed to every imaginable force, from surface tension to electro-osmosis, without much evidence to support any of the hypotheses.

Early in college training, Prof. E. A. Andrews directed my attention to the movement of protoplasmic particles. He referred particularly to a form of activity which was neither cyclosis nor the "vulgar pedesis dance discovered by Brown in dead regions of plants. These particles", said Prof. Andrews, "are travelers, going places". In ciliated Protozoa of the closely related families Vorticellidæ and Stentoridæ there are particles less than $1 \mathrm{~m} \mu$ in diameter which move ten to one hundred times their own length in a second or two. They may pass close to one another, proceeding in opposite directions ${ }^{1}$.

In subsequent years my attention was centred on the flow of protoplasm. Recently, I again turned to the particles, hoping to find in their motion a clue to the mechanism of protoplasmic streaming. Isolated cells from cultures of plant 'cancers'. served as material-kindly supplied by Dr. R. J. Gautheret.

Some years ago $\mathrm{I}^{2}$ advanced a theory of protoplasmic flow based on the rhythmic pulsations of a slime mould. The peristaltic waves, when accelerated by time-lapse photography, are readily seen. They much resemble the trains of waves in a stimulated muscle fibre. There is no question of the presence of rhythmic pulsations; but, though synchronized with the fifty-second period in reversal of flow, they are not the cause of cyclosis. One of the weaknesses of the theory was its failure to explain the simultaneous flow of protoplasm in opposite directions in parallel currents. One occasionally sees in Protozoa, but better still in a sheet of protoplasm in some species of slime moulds, as many as nine channels of flow in which adjoining currents flow in opposite directions, 'rubbing shoulders' as it were, without mixing, and without an evident wall between the two (top centre in the accompanying figure).

All the foregoing difficulties were apparently solved by a 'new' theory of cyclosis which appeared several years ago in four articles from the pens of six authors ${ }^{3-6}$. Frey-Wyssling ${ }^{3}$ deserves credit for the theory, though Meyer and Mark ${ }^{6,7}$ claimed a twentyyear priority, in so far as the theory applies to muscular contraction. The suggestion made by all six authors is that within the protoplasmic stream polypeptide chains fold and unfold, the protein molecules moving forward like an army of caterpillars, carrying the surrounding medium with them.

The curling and uncurling of molecular fibres is an attractive mechanism by which to account for the flow of protoplasm. It is, however, a pure assumption, permissible only if certain conditions are met. Curling may be accounted for ; thermic agitation will do it. Stretching, however, is another matter. At every point where folding occurs sufficient energy must be transmitted to stretch, or untwist, the folded chain in opposition to thermic agitation. The 